\title{
Evaluation of a Novel Pulpotomy Technique with a Low-level Laser Therapy and Its Comparison with Mineral Trioxide Aggregate and Pulpotec: An Animal Trial
}

\author{
${ }^{1}$ AR Prabhakar, ${ }^{2}$ Chandrashekar Yavagal, ${ }^{3}$ Amitha M Shagale
}

\begin{abstract}
Introduction: Pedodontists have always looked for newer techniques, safer materials, and ergonomic technologies to treat pulpal infections so as to help children heal faster. Low-level laser is one such innovation that needs to be assessed for its efficacy as a potential pulpotomy medicament.
\end{abstract}

Aim: To evaluate the histological changes in the dental pulp of dog's primary premolars after pulpotomy using low-level diode laser therapy (LLLT) in comparison with mineral trioxide aggregate (MTA), and Pulpotec.

Design: In this experimental study, 30 teeth were randomly selected from five dogs. The animals were anesthetized and pulpotomized using LLLT, MTA, and Pulpotec respectively. One week later, the pulpotomized teeth were extracted and subjected to histological evaluation for inflammation. Histological changes seen in the pulp tissues of all the groups were subjected to statistical analysis using Kruskal-Wallis test for groupwise analysis ( $p$-value of $<0.001)$ and for pairwise Mann-Whitney $U$ test ( $p$-value of $<0.05)$.

Results: On histologic observations, least inflammation was seen in low-level laser group followed by Pulpotec. Severe inflammatory cell infiltrates were seen in MTA.

Conclusion: Low-level laser therapy appears to be a safe, minimally invasive, yet an effective modality for pulpotomy followed by Pulpotec.

Keywords: Low level laser therapy, Mineral trioxide aggregate, Pulpotec, Pulpotomy.

How to cite this article: Prabhakar AR, Yavagal C, Shagale AM. Evaluation of a Novel Pulpotomy Technique with a Low-level Laser Therapy and Its Comparison with Mineral Trioxide Aggregate and Pulpotec: An Animal Trial. Int J Laser Dent 2015;5(3):58-62.

\section{Source of support: Nil}

Conflict of interest: None

\section{INTRODUCTION}

With the turn of the new millennium, our understanding of the importance of preserving natural teeth has been

${ }^{1}$ Professor and Head, ${ }^{2}$ Reader, ${ }^{3}$ Postgraduate Student (3rd Year)

${ }^{1-3}$ Department of Pedodontics and Preventive Dentistry, Bapuji Dental College and Hospital, Davangere, Karnataka, India

Corresponding Author: Amitha M Shagale, Postgraduate Student (3rd Year), Department of Pedodontics and Preventive Dentistry, Bapuji Dental College and Hospital Davangere, Karnataka, India, Phone: +918192220572, e-mail: amithamshagle@gmail.com further reinforced. Although preventive strategies are being pursued vigorously, many teeth are still being lost at an early age because of caries. Preservation of primary teeth until the eruption of permanent teeth is of utmost importance since they maintain the shape of the dental arches, hold the space for succedaneous teeth, prevent detrimental tongue and speech habits, preserve esthetics, as well as maintain function. Hence, primary teeth with caries should ideally be restored rather than extracted. ${ }^{1}$

Pulpotomy is a well-recognized conservative primary endodontic procedure achieved by the amputation of the inflamed/infected coronal pulp tissues that get exposed during caries excavation or due to trauma. The objective of this treatment is to remove the coronal pulp laden by microbes, thereby allowing healing to take place at the entrance of the root canals while maintaining the vitality of the radicular tissue underneath. In doing so, the pulp stumps need to be treated with certain medicaments that promote healing and help in preserving the vitality of the tooth. ${ }^{2}$

Traditionally, formocresol has been regarded as the gold standard pulpotomy medicament. However, its use has been questioned recently owing to several concerns viz., carcinogenicity, mutagenicity, and cytotoxicity. ${ }^{2}$ So, the quest is on for newer materials and technologies, which can provide more biocompatible alternatives to formocresol. ${ }^{3}$

Studies have shown that mineral trioxide aggregate (MTA) introduced by Mahmoud Torabinejad at Loma Linda University, as one of the most adaptable materials in the field of dentistry because of its numerous exciting clinical applications. Mineral trioxide aggregate exhibits good physical properties and stimulates tissue regeneration, thus providing an excellent overall prognosis. ${ }^{4,5}$ However, MTA has issues with its ease of usage. Pulpotec is another newer pulpotomy medicament that is relatively simple to use, and has thus far provided successful outcomes in both primary and permanent teeth. ${ }^{6}$ However, there is paucity of literature on this innovative material for it to be included in the list of "ideal" pulpotomy medicaments.

The recent technological progress aimed at preserving pulpal vitality justifies the use of lasers in pediatric 
endodontics. The laser wavelengths studied thus far have all been successful in improving the clinical and biological outcomes because of their inherent wound conditioning ability, disinfection, tubular sealing as well as excellent hemostasis. However, low-level lasers have additional advantages of being minimally invasive, inherently safe, and effective in procedural analgesia, thus taking them a step ahead of all other surgical lasers that have been tried for pulpotomy so far. ${ }^{7}$

Hence, to resolve the conflict of choosing the "Ideal" pulpotomy material/technique, the present research was undertaken to comprehensively evaluate the histological changes in the dental pulps of the primary premolars of dogs after pulpotomy with low-level diode laser therapy (LLLT) in comparison to MTA and Pulpotec.

\section{MATERIALS AND METHODS}

\section{Study Design}

It is an experimental, in vivo, and animal trial.

\section{Study Setting}

This study was carried out at the Department of Pedodontics and Preventive Dentistry, Bapuji Dental College and Hospital, in association with Government Veterinary Hospital and Animal Husbandry, Davangere, India.

\section{Methodology}

Thirty healthy 8-week-old dog's primary premolars were selected for the study with the aid of a veterinary surgeon, after getting ethical approval from the Institutional Review Board. Strict adherence to the inclusion criteria was observed. Only those animals that had undergone prior vaccination against life-threatening diseases were included in the study. Similarly only those dogs that had sound premolars were selected. Thirty premolars thus selected were randomly allocated using lottery dip method and further divided into three experimental groups.

Group I: 10 premolars for LLLT

Group II: 10 premolars for MTA

Group II: 10 premolars for Pulpotec.

\section{Preanesthetic Evaluation and Preparation of Animals}

After a thorough evaluation from the veterinary surgeon, the animals were fed with solid food 12 hours prior to the procedure and were kept nil per oral for 6 hours. General anesthesia was employed with intramuscular injection of $20 \mathrm{mg} / \mathrm{kg}$ of ketamine HCL and $12 \mathrm{mg} / \mathrm{kg}$ of Xylazine. An infiltration injection of xylocaine, $2 \%$ was used for achieving local anesthesia. ${ }^{8}$

\section{Clinical Procedure}

Once anesthesia was achieved, the cavity preparation was done on the selected teeth and the pulp chamber was exposed using a high-speed no. 4 round bur. The same bur was used to penetrate the coronal pulp, parallel to the long axis of the tooth. The coronal pulp was then removed using a small size $(1 \mathrm{~mm})$ sharp spoon excavator followed by copious irrigation with saline. Primary hemostasis was achieved by placing sterile saline-soaked cotton pellets on the radicular pulp under light pressure for 5 minutes.

In the LLLT group, complete hemostasis was achieved by exposing root canal orifices to $660 \mathrm{~nm}$ diode laser (Silberbauer Low Level Laser, Austria) of 0.036 W output, delivered by an optical laser headpiece for 4 minutes, followed by the placement of a zinc oxide and eugenol base (Fig. 1). ${ }^{9}$

In the MTA group - the MTA Angelus (Angelus, Londrina, Brazil) paste was obtained by mixing powder and water to obtain a putty consistency, which was then placed onto the root canal orifices. It was condensed lightly with a moistened cotton pellet, followed by the placement of a layer of zinc oxide eugenol base.

In the Pulpotec group - Pulpotec (Produits Dentaires, SA, Vevey, Switzerland) liquid and powder were blended to obtain a thick, yet creamy consistency of the paste, which was then inserted onto the canal orifices and sealed. Postoperatively, the animals were kept under the supervision of a veterinary surgeon until discharge.

After 1 week, 30 pulpotomized premolars from the dogs were extracted. All these specimens were fixed in $10 \%$ buffered formalin for 2 days, and subsequently decalcified using 10\% nitric acid. The teeth were then processed, sectioned, and stained with hematoxylin and eosin for histological assessment. The sections were observed under an optical light microscope by a trained and calibrated oral pathologist. 8,9

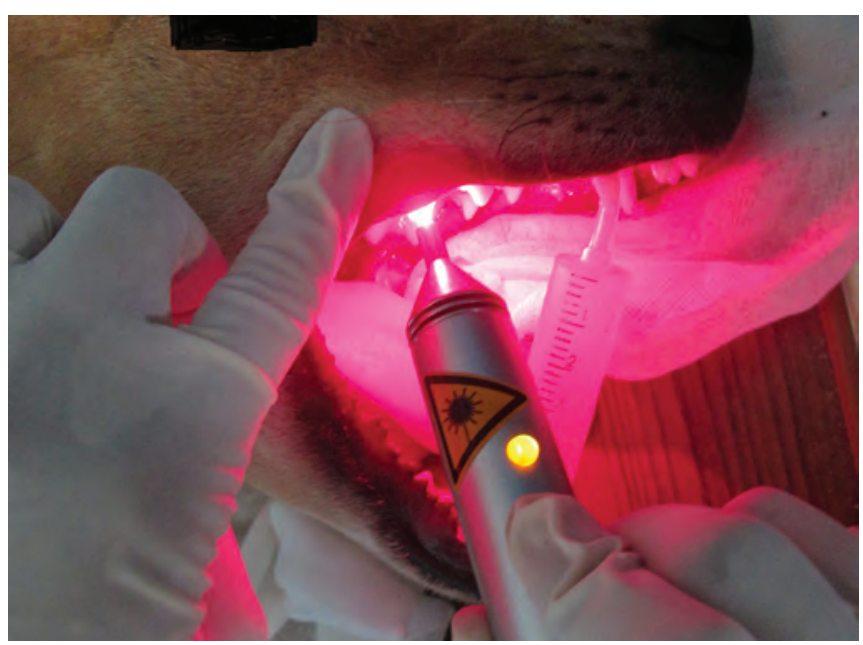

Fig. 1: Application of low-level diode laser 


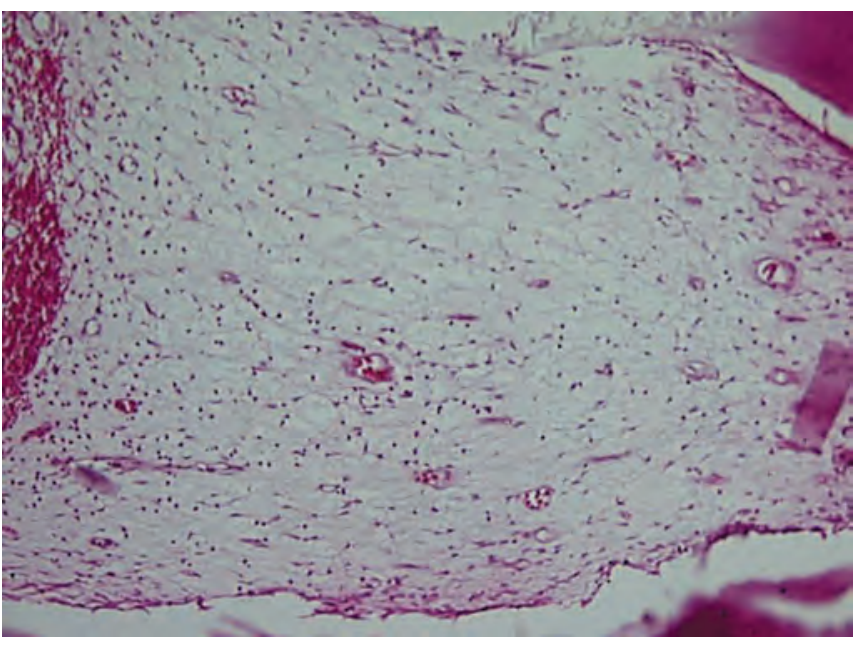

Fig. 2: Histological picture showing least inflammation in low-level laser group

The histopathological changes were assessed using the following criteria:

$1=$ absent or very few inflammatory cells (PMNs);

$2=$ mild, defined as an average of $<10$ inflammatory cells (PMNs);

$3=$ moderate, defined as an average of 10 to 25 inflammatory cells (PMNs);

4 = severe, defined as an average $>25$ inflammatory cells (PMNs). ${ }^{9}$

\section{Statistical Analysis}

Statistical analysis was carried out using Statistical Package for the Social Sciences (SPSS) version 16. Results were subjected to statistical analysis using KruskalWallis test for groupwise analysis ( $\mathrm{p}$-value of $<0.001$ ) and for pairwise Mann-Whitney U test ( $p$-value of $<0.05$ ).

\section{RESULTS}

Based on light microscopic observations, least inflammation was seen in group I, LLLT (Fig. 2), followed by group III, Pulpotec (Fig. 3). Severe inflammatory cell infiltrates were seen in group II, MTA (Fig. 4, Table 1).

On pairwise comparison, it was found that group I showed statistically significant results in comparison to group II $(\mathrm{p}<0.001)$ and group III $(\mathrm{p}<0.001)$. Group II showed statistically significant results in comparison to group III $(\mathrm{p}<0.002)$ (Table 2$)$.

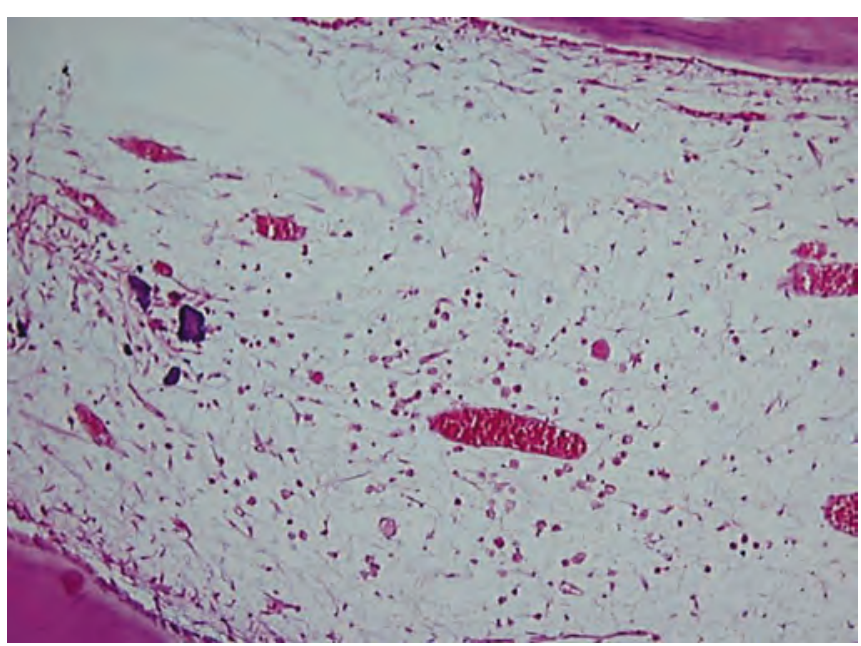

Fig. 3: Histological picture showing mild inflammation in Pulpotec group

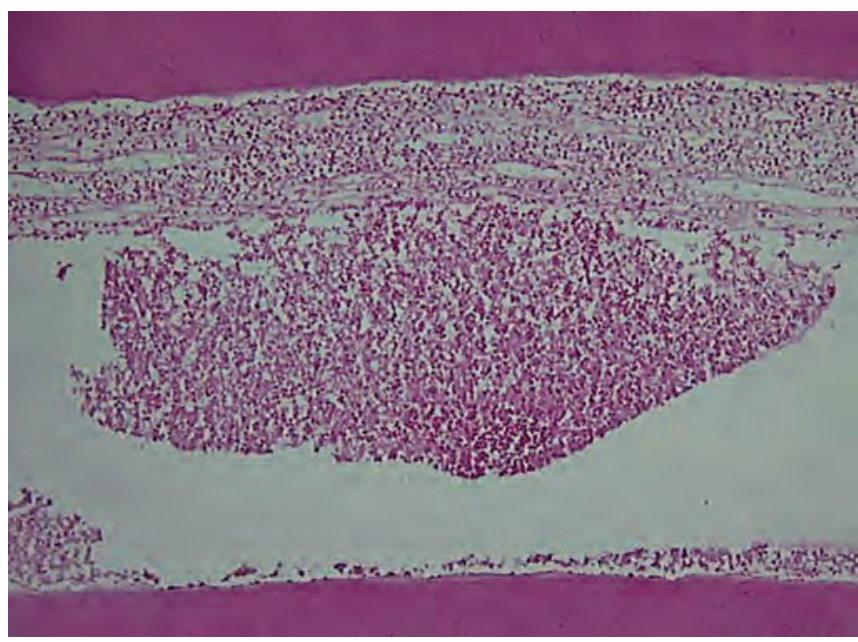

Fig. 4: Histological picture showing severe inflammation in MTA group

Table 1: Histopathological findings of LLLT, MTA, and Pulpotec. Ten samples for each group

\begin{tabular}{llllll}
\hline & No & & & & \\
& inflammation & Mild & Moderate & Severe & Total \\
\hline Group I: LLLT & 9 & 1 & 0 & 0 & 10 \\
Group II: MTA & 0 & 1 & 7 & 2 & 10 \\
Group III: Pulpotec & 0 & 8 & 2 & 0 & 10 \\
& & Chi-square value $(\mathrm{df})^{\#}=23.66(2), \mathrm{p}<0.001$ \\
\hline
\end{tabular}

"Kruskal-Wallis test, $p<0.001$ statistically significant

Table 2: Pairwise comparison of study groups using Mann-Whitney $U$ test

\begin{tabular}{|c|c|c|c|c|c|c|c|}
\hline & \multirow[b]{2}{*}{$n$} & \multirow[b]{2}{*}{$\begin{array}{l}\text { Median } \\
\text { (Q1-Q3) }\end{array}$} & \multicolumn{2}{|c|}{ Kruskal-Wallis test } & \multicolumn{3}{|c|}{ Pairwise comparison } \\
\hline & & & $\begin{array}{l}\text { Chi-square } \\
\text { value (df) }\end{array}$ & $p$-value & $\begin{array}{l}\text { Group I vs } \\
\text { Group II }\end{array}$ & $\begin{array}{l}\text { Group II vs } \\
\text { Group III }\end{array}$ & $\begin{array}{l}\text { Group I vs } \\
\text { Group III }\end{array}$ \\
\hline Group I: LLLT & 10 & $0(0-0)$ & $23.66(2)$ & $<0.001^{\star}$ & $\begin{array}{l}\text { U statistic }{ }^{\#}=0.5, \\
p<0.001^{*}\end{array}$ & $\begin{array}{l}\text { U statistic }{ }^{\#}=4.00 \\
p<0.001^{*}\end{array}$ & $\begin{array}{l}\text { U statistic }{ }^{\#}=13.00 \\
p=0.002^{*}\end{array}$ \\
\hline Group II: MTA & 10 & $2(2-2.25)$ & & & & & \\
\hline Group III: Pulpotec & 10 & $1(1-1.25)$ & & & & & \\
\hline
\end{tabular}




\section{DISCUSSION}

The rationale behind a pulpotomy is to preserve primary teeth in a vital state so as to enable them to fulfil their roles as space maintainers till the eruption of their permanent successors. An ideal pulpotomy medicament should have the property of stimulating the remaining pulp tissue, thereby preserving the vitality and function of radicular pulp. ${ }^{9,10}$ Histologically, intact odontoblasts' lined dentin chamber should be formed, thus aiding the tooth to take part in a normal exfoliative process at the appropriate time. ${ }^{11}$ In spite of a wide array of materials and techniques, formocresol is still regarded as the gold standard material for pulpotomies of primary teeth. The reasons for this could be its ease of availability, bacteriostatic nature, and superior fixative property, thrusting an impressive success rate of 70 to $90 \% .^{12}$ Despite its excellent clinical record, formocresol has shown potential toxic effects, such as mutagenicity, carcinogenicity, and immune sensitization, thus reiterating the need for an alternate pulpotomy medicament. ${ }^{13}$ In this regard, MTA and Pulpotec have shown reasonable evidence as potential formocresol-replacements and hence they were included in the present study. They were compared with a novel low-level laser that was operated at an ultra-safe power setting so as to make a clinical extrapolation viable at a later date.

In order to assess the clinical success and therapeutic outcome of any pulpotomy medicament, clinical and radiographic findings are usually employed. But in order to know the true histologic response of the dental pulp, a thorough histopathological evaluation is needed which may not be feasible with human subjects, especially those belonging to the pediatric age group. Many previous studies have demonstrated the histological similarity between human and canine dental pulps. ${ }^{14}$ Hence, the present intervention was conducted on the primary premolars of healthy dog's coinciding with their time of natural exfoliation.

The results of the present intervention affirmed that LLLT reduces inflammation as evidenced by the lack of it in most of the samples. This is scientifically plausible and easy to explain as all low-level laser wavelengths have potent antiinflammatory, analgesic, and hemostatic abilities. These findings implicate a positive healing outcome, thus preserving the vitality of the radicular pulp. In addition to this, LLLT gives a whole new dimension to primary endodontics as it is noninvasive and a nonpharmacological entity offering superior therapeutic benefits, such as lack of bleeding, faster healing, adequate analgesia, and reduced postoperative infection. ${ }^{15}$ Previous researchers Sun and Tuner ${ }^{16}$ have reported that LLLT provides many positive postoperative outcomes like accelerated wound healing, regeneration, relief of pain, and enhancement of local immunity. Previous studies on the topic by Todea et $\mathrm{al}^{7}$ and Mareddy et $\mathrm{al}^{9}$ have also shown that laser therapy stimulates the odotoblastic cells by activating the cell signaling molecules, such as Smads, a class of proteins, which help in modulating the activity of the transforming growth factor beta ligands, ultimately leading to mineralization and formation of tertiary dentin.

Mineral trioxide aggregate, first introduced by Mahmoud Torabinejad, was originally formulated to provide the physical properties, setting requirements, and characteristics necessary for an ideal repair material. However, further research on MTA revealed that apart from good sealing ability, excellent long-term prognosis and good biocompatibility; it favored tissue regeneration as well. ${ }^{4}$ In our study, MTA (group II) exhibited moderate to severe inflammatory cell infiltrates, i.e., out of 10 samples 7 showed moderate, 2 showed severe, and 1 showed mild inflammation. These histologic findings are similar to previous observations made by Caicedo et al. ${ }^{1}$ This phenomenon could be explained by understanding the setting mechanism of MTA. The $\mathrm{pH}$ of MTA is 10.2 during the placement, which then increases to 12.5 once it sets. ${ }^{17}$ This high alkalinity probably overstimulates the primary pulp causing pulpal metaplasia, formation of odontoclasts, and chronic inflammation. ${ }^{1,9}$ However, this inflamed but vital pulp has been shown to return to a healthy, functional status after MTA pulpotomy. ${ }^{18}$ Pulpotec is a newer radiopaque, filling paste which is composed of polyoxymethylene, iodoform, dexamethasone acetate, formaldehyde, phenol, guaiacol, and excipient. ${ }^{3,19}$ In our study, out of 10 samples, 8 samples showed very mild inflammation whereas only 2 samples showed moderate inflammation. These findings could be explained based on the presence of dexamethasone acetate as one of the constituents of this medicament. In the present study, we observed some areas of calcified masses in a few samples similar to what was previously reported by Pranitha Kakarla. This observation could be due to the activity of odontoblast-like cells arising from the undifferentiated mesenchyme ultimately depositing a dentin-like material. ${ }^{3}$ The unique feature of this newer medicament is that it ensures an aseptic field of action due to cicatrization of the pulpal stump at the chamber canal interface while preserving the vitality of the underlying radicular tissue. ${ }^{6}$

\section{CONCLUSION}

Within the parameters tested in the present intervention, LLLT appears to be a safe, minimally invasive, yet an effective modality for pulpotomy. Between MTA and Pulpotec, the later seems to far better for more 
reasons than one. However, further long-term human clinical trials are needed to effectively seal the fate of formocresol by finding the Holy-Grail of pulpotomy medicament.

What this paper adds:

- An innovative nonpharmacologic pulpotomy option

- Objective comparison between two contemporary medicaments.

Histologic assessment - the "true" measure of any pulpotomy intervention.

Why this paper is important for pediatric dentists:

- Low-level laser therapy offers a nonpharmacologic, yet quintessential pulpotomy outcome

- Low-level/soft laser therapy is the future of noninvasive pediatric dentistry and pediatric endodontics.

\section{REFERENCES}

1. Caicedo R, Abbott PV, Alongi DJ, Alarcon MY. Clinical, radiographic and histological analysis of the effects of mineral trioxide aggregate used in direct pulp capping and pulpotomies of primary teeth. Aust Dent J 2006 Dec;51(4): 297-305.

2. Lin PY, Chen HS, Wang YH, Tu YK. Primary molar pulpotomy: a systematic review and network meta-analysis. J Dent 2014 Sep;42(9):1060-1077.

3. Kakarla P, Avula JS, Mellela GM, Bandi S, Anche S. Dental pulp response to collagen and pulpotec cement as pulpotomy agents in primary dentition: a histological study. J Conserv Dent 2013 Sep;16(5):434-438.

4. Rao A, Shenoy R. Mineral trioxide aggregate - a review. J Clin Pediatr Dent 2009 Fall;34(1):1-7. Review.

5. Nowicka A, Lipski M, Parafiniuk M, Sporniak-Tutak K, Lichota D, Kosierkiewicz A, Kaczmarek W, BuczkowskaRadlińska J. Response of human dental pulp capped with biodentine and mineral trioxide aggregate. J Endod 2013 Jun;39(6):743-747.

6. Kareem MA. A clinical and histopathological evaluation of different pulpotomy agents in primary teeth. College of Dentistry, AL-Mustansiria University.
7. Todea C, Kerezsi C, Balabuc C, Calniceanu M, Filip L. Pulp capping - conventional to laser-assisted therapy (I). J Oral Laser Appl 2008;8(2):71-82.

8. Jabbarifar E, Razavi SM, Ahmadi N. Histopathologic responses of dog's dental pulp to mineral trioxide aggregate, bio active glass, formocresol, hydroxyapatite. Dent Res J 2007 Autumn-Winter;4(2):83-87.

9. Mareddy A, Mallikarjun SB, Shetty PV, Vanga V, Rao N, Chandru TP. Histological evaluation of diode laser pulpotomy in dogs. J Oral Laser Appl 2010;10:7-16.

10. Witherspoon DE, Small JC, Harris GZ. Mineral trioxide aggregate pulpotomies: a case series outcomes assessment. J Am Dent Assoc 2006 May;137(5):610-618.

11. Ibricevic $\mathrm{H}, \mathrm{Al}$ Jane Q. Ferric sulphate as pulpotomy agent in primary teeth; 20 month clinical follow up. J Clin Pediatr Dent 2000 Summer;24(4):269-272.

12. Patchett CL, Srinivasan V, Waterhouse PJ. Is there life after Buckley's formocresol? Part II-Development of a protocol for the management of extensive caries in the primary molar. Int J Paediatr Dent 2006 May;16(3):199-206.

13. Saltzman B, Sigal M, Clokie C, Rukavina J, Titley K, Kulkarni GV. Assessment of a novel alternative to conventional formocresol-zinc oxide eugenol pulpotomy for the treatment of pulpally involved human primary teeth: diode laser-mineral trioxide aggregate pulpotomy. Int J Paediatr Dent 2005 Nov;15(6):437-447.

14. Hale FA. Hale Veterinary Clinic. 1997 Jan. p. 1-3. Available from: http://www.toothvet.ca. Accessed on 2 Jan. 2014.

15. Golpayegani MV, Ansari G, Tadayon N, Shams S, Mir M. Low-level laser therapy for pulpotomy treatment of primary molars. J Dent Tehran Univ Med Sci 2009 Feb;6(4):168-174.

16. Sun G, Tuner J. Low-level laser therapy in dentistry. Dent Clin North Am 2004 Oct;48(4):1061-1076.

17. Parirokh $\mathrm{M}$, Torabinejad $\mathrm{M}$. Mineral trioxide aggregate: a comprehensive literature review - Part I: chemical, physical, and antibacterial properties. J Endod 2010 Jan;36(1):16-27.

18. Chueh L-H, Chiang C-P. Histology of irreversible pulpitis premolars treated with mineral trioxide aggregate pulpotomy. Oper Dent 2010 May-Jun;35(3):370-374.

19. Al-Salman KA, Al-Rawi BA, Rahawi OS. The effectiveness of using pulpotec $\AA$ in treatment of pulpitis by pulpotomy of vital deciduous molar and vital immature permanent molar. Al-Rafidain Dent J 2012;12(1):185-190. 